\title{
Altemeier and Delorme procedures are efficacious and safe for treatment of Rectal Prolapse:A Retrospective Analysis
}

HouDong Wang

Department of Colorectal Surgery, The Third People's Hospital of Hangzhou

\section{Xiu-Feng Zhang}

Department of Colorectal Surgery, The Third People's Hospital of Hangzhou

\section{Shu-Xian Shao}

Department of Colorectal Surgery, The Third People's Hospital of Hangzhou

Zhong Shen ( $\square 996891171 @ q q . c o m$ )

Department of Colorectal Surgery, The Third People's Hospital of Hangzhou

\section{Research Article}

Keywords: Altemeier, Delorme, perineal procedure, Rectal prolapse

Posted Date: February 21st, 2022

DOI: https://doi.org/10.21203/rs.3.rs-1211318/v1

License: (a) (i) This work is licensed under a Creative Commons Attribution 4.0 International License. Read Full License 


\section{Abstract}

Purpose To compare the safety and efficacy of Altemeier and Delorme procedures for treatment of mild full-thickness rectal prolapse.

Methods A total of 34 patients, diagnosed with rectal prolapse and who underwent Altemeier and Delorme procedures between January 2011 to December 2019, were included in the study. We evaluated each patient's clinical characteristics, operative outcomes and follow-up data then compared them between groups.

Results Both procedures were successfully completed in all recruited patients, with no significant differences observed between the groups with regards to age, sex, disease course, body mass index (BMI) and American Society of Anesthesiologist (ASA) score $(p>0.05)$. However, squat maximal prolapse length was significantly lower in Delorme $(5.4 \pm 1.6 \mathrm{~cm})$ than in the Altemeier $(9.3 \pm 2.3 \mathrm{~cm})$ group $(t=5.89, p$ $\llbracket 0.01)$. Similarly, operative time was significantly shorter in the Delorme $(85.8 \pm 13.7 \mathrm{~min})$ than in the Altemeier (111.0 $\pm 14.2 \mathrm{~min} ; t=5.26, \mathrm{p} \otimes 0.01)$ group, while intraoperative blood loss was significantly lower in the Delorme $(20.8 \pm 6.5 \mathrm{ml})$ than Altemeier $(61.7 \pm 9.4 \mathrm{ml}, t=14.98, p<0.01)$. However, we found no significant differences in the incidence of postoperative complications, including bleeding, anastomotic stricture, anastomotic leakage, urinary retention, urinary tract infection between the Delorme $(16 \%)$ and Altemeier $(20 \%)$ groups $(P=0.10, p=0.75)$. Notably, patients in the Delorme group had significantly shorter postoperative hospital stay ( $8.4 \pm 1.5$ days) relative to those in the Altemeier group (11.0 \pm 2.2 days) $(t=4.13, p \otimes 0.01)$. We found no significant differences in follow-up times between Delorme $(16.3 \pm 2.3$ months) and Altemeier (15.0 \pm 3.3 months) groups $(t=1.38, p=0.18)$, as well as overall success rates (Delorme $=89.5 \%$; Altemeier $=86.7 \%, \mathrm{u}=0.06, \mathrm{p}=0.80$ ). A total of 5 and 4 patients from the Delorme and Altemeier groups, respectively, exhibited constipation symptoms. Compared with before operation, the Wexner constipation score decreased in both groups (Delorme $=23.6 \pm 2.5$ vs.11.0 $\pm 2.0, t=24.71, p \otimes 0.01$; Altemeier $=23.5 \pm 1.3$ vs.9.3 $\pm 1.7, t=13.83, p \otimes 0.01)$. Moreover, fecal incontinent symptoms were described in 6 and 5 patients of Delorme group and Altemeier group, respectively. Postoperative Wexner fecal incontinence scale scores were significantly lower in the two groups than those before operation (Delorme $=14.8 \pm 1.5$ vs.6.2 $\pm 0.8, t=14.10, \mathrm{p} \bowtie 0.01$; Altemeier=15.6 \pm 1.1 vs.6.8 $\pm 2.3, t=10.23 \llbracket p \otimes 0.01$ ).

Conclusion Our results affirm the efficacy and safety of both Altemeier and Delorme procedures in treatment of rectal prolapse, for improved defecation status in patients with faecal incontinence and constipation. Delorme procedure is recommended for patients with mild prolapse, owing to quicker recovery, shorter hospital stay, and fewer anastomotic complications, relative to Altemeier.

\section{Introduction}

Rectal prolapse is a disorder characterized by a intussusception of the rectal wall, which protrudes externally through the anus. A spectrum of coexisting anatomic abnormalities, such as an abnormally deep Douglas' pouch, a redundant sigmoid colon and diastasis of the levator ani, may also occur in 
patients with rectal prolapse, and subsequently cause progressive loss of function of pelvic floor structures. Approximately $44-66 \%$ of patients with rectal prolapse also manifest fecal incontinence, while $38-79 \%$ of them exhibit constipation ${ }^{[1-4]}$. Incontinence in this group of patients has been linked to presence of the prolapsing tissue, which can cause chronic traumatic stretch of the sphincter, and continuously stimulate the rectoanal inhibitory reflex thereby causing sphincter dysfunction ${ }^{[5]}$. The prolapse segment in the rectum generates a blockage, which gives rise to fecal constipation.

Over 100 operational options have been developed for treatment of this disease ${ }^{[6]}$. To date, however, no consensus has been reached with regards to the ideal surgical method. Surgical approaches for repairing rectal prolapse can be generally classified into either perineal and abdominal categories. Perineal approaches have a low surgical risk and acceptable rates of recurrence, hence are considered suitable for patients with high operation risk. The most common perineal procedures include Altemeier, Delorme and stapled resection ${ }^{[7]}$. Stapled resection procedure, which only considers excising the mucosa of the prolapsed segment, is often used for treatment of rectal mucosal prolapse rather than full-thickness rectal wall prolapse ${ }^{[8]}$. Delorme procedure comprises sleeve resection of the mucosa and folding the muscular layers, while Altemeier, which is also called perineal rectosigmoidectomy, entails removal of the redundant colorectum and reconstruct the pelvic floor ${ }^{[9]}$. Although both procedures are considered suitable for patients with mild full-thickness prolapse and high risk of abdominal surgery, international guidelines do not precisely indicate which therapy is better for this group of patients. Besides, previous reports have suggested that both procedures have similar recurrence rates ${ }^{[10]}$.

In the current study, we aimed to compare the safety and efficacy of Altemeier and Delorme procedures for treatment of patient with mild full-thickness rectal prolapse.

\section{Methods}

The Ethical Committee of The Third People's Hospital of Hangzhou approved the study protocol. Written informed consent for participation was obtained in accordance with institutional review board standards according to the Declaration of Helsinki. Thirty-four patients with full-thickness rectal prolapse, who received either Altemeier or Delorme procedures, between January 2011 and December 2019, at The Third People's Hospital of Hangzhou, China, were recruited in the study. We collected their demographic data, including age at surgical treatment, gender, disease course, BMI, ASA score, squat maximal prolapse length, operative data such as operative time, intraoperative blood loss, postoperative complications, and postoperative length of hospital stay, as well as follow-up data, including recurrence rate, Wexner constipation score and Wexner fecal incontinence scale. Technical safety of eaprocedure was assessed by analyzing operative times, intraoperative blood loss, postoperative complications and postoperative length of hospital stay. Furthermore, we evaluated measures of effectiveness of the interventions, including recurrence rate, Wexner constipation score and Wexner fecal incontinence scale. Furthermore, all patients were subjected to colonoscopy, to exclude other associated pathology, as well as mechanical 
bowel preparation and prophylactic antibiotic therapy. All operations were performed by the same team of doctors.

\section{Surgical procedure}

\section{Delorme Procedure}

All the patients who underwent Delorme procedure were first placed in a lithotomy position, after spinal/epidural anesthesia. Briefly, the surgical area was routinely disinfected and sterile drapes placed. The anal canal was immobilized with a 2-0 traction suture, from the right anterior, right posterior, left anterior, and left posterior directions, and the dentate line identified. The prolapsed rectum was carefully brought out, through the anal orifice, the mucosa removed and assessed (about twice the length of the prolapse part of the rectum). A diluted $(1: 200,000)$ epinephrine solution was then injected into the submucosa, near the dentate line, to reduce intraoperative bleeding and facilitate dissection. Thereafter, circumferential resection margin was marked at about $2 \mathrm{~cm}$ above the dentate line using an electrocautery (Fig. 1a). The mucosa of outer rectum wall was cut from the anterior, lateral and posterior walls, then its sleeve resection performed from the underlying muscle wall to the apex of the prolapsing bowel submucosal dissection (Fig. 1b-1d). The muscular layer was folded longitudinally, by suturing with absorbable 3.0 vicryl sutures, using simple interrupted stitches (Fig. 1e), then an anal sphincteroplasty also performed using multiple interrupted absorbable sutures (Fig. 1f). Finally, mucosal edges were approximated using simple interrupted stitches (Fig. 1g). No obvious rectal prolapse was observed after Delorme procedure(Fig. 1h).

\section{Altemeier Procedure}

Patients were positioned in a lithotomy position, and surgery performed under either general or spinal anesthesia. The prolapsed colorectum exhibited a tower-like morphology (Fig. 2a). The anal canal was immobilized using a 2-0 traction suture, from the right anterior, right posterior, left anterior, and left posterior directions, and the dentate line identified. The prolapsed rectum was carefully brought out through the anal orifice, and a circumferential resection margin marked at about $1.5 \mathrm{~cm}$ above the dentate line via electrocautery (Fig. 2 b). The outer rectum was then cut from the anterior, lateral and posterior walls using an ultrasonic scalpel (Fig. 2c), then an incision performed through the peritoneum to gain access to the peritoneal cavity (Fig. 2d). The mesorectum, superior rectal artery and sigmoid arteries were also dissected using an ultrasonic scalpel, followed by ligation of the superior rectal and partial sigmoid arteries (Fig. 2e-2f). The peritoneum and the anterior sigmoid wall were sutured at the pouch of Douglas with absorbable 3.0 vicryl sutures using simple interrupted stitches, to reconstruct and elevate the pelvic floor (Fig. 2g). Thereafter, levatorplasty, comprising plication of the levator ani musculature, was performed using interrupted absorbable sutures (Fig. 2h). Cuts were carefully made along the sigmoid wall, about $1 \mathrm{~cm}$ above the dentate line, with an end-to-end anastomosis between the rectum and sigmoid also performed simultaneously (Fig. 2i). Finally, the redundant rectum and sigmoid were removed. A drainage tube was placed above the anastomosis for 2 days (Fig. 2j). 


\section{Postoperative care}

Patients were administered with oral liquid intake, at 6 hours post-operation, while a semiliquid diet started 3 days after surgery. Patients were intravenously injected with antibiotics at 3 days postoperation. Those without postoperative complications, such as bleeding, anastomotic stricture, anastomotic leakage, urinary retention, and urinary tract infections were discharged. Follow-up was conducted via outpatient reviews or telephone. Bowel function, including incontinence, and constipation, was reassessed at the clinic at 1 month post-operation, and full thickness prolapse of the rectal wall defined as recurrence of the disease.

\section{Statistical analysis}

All statistical analyses were performed using Statistic Package for Social Science (SPSS) v17.0 software (SPSS Inc., Chicago, IL, USA), and all data presented as means with their respective standard deviations. Kolmogorov-Smirnov and Levene tests were used to test normality and homogeneity of variance.

Dichotomous variables were subjected to the McNemar chi-square, Pearson's chi-square or Fishers' exact tests. Comparisons between two sample means, before and after treatment, were performed using a paired $t$-test. Data followed by $\mathrm{P}<0.05$ were considered statistically significant.

\section{Results}

\section{Patient demographics}

All the 34 patients, recruited herein, successfully underwent the aforementioned procedures. Seven males $(36.8 \%)$ and 12 females (63.2\%), with a median age of $62.0 \pm 6.2$ years, underwent Delorme surgery, whereas 4 males and 11 females, with a median age of $60.6 \pm 6.5$ years, underwent the Altemeier procedure. We found no significant differences with regards to the age and sex of patients between the two groups. However, in the Delorme group exhibited significantly longer squat maximal prolapse $(5.4 \pm 1.6 \mathrm{~cm})$ than those in the Altemeier group $(9.3 \pm 2.3 \mathrm{~cm})(t=5.89, p<0.01)$ (Table 1). Five and four patients in the Delorme and Altemeier groups, respectively, reported constipation with corresponding Wexner constipation scores of $23.6 \pm 2.5$ and $23.5 \pm 1.3(t=0.07, p=0.95)$ (Table 2). Similarly, no significant differences were observed in fecal incontinence between the 6 patients in the Delorme and 5 in the Altemeier groups, as evidenced by Wexner fecal incontinence scale scores of $14.8 \pm 1.5$ and $15.6 \pm 1.1$, respectively $(t=0.95, p=0.37)$ (Table 3 ).

\section{Operative outcomes}

We found no evidence of either intraoperative complications or mortality after operations. Conversely, the Delorme procedure required an operative time of $85.8 \pm 13.7 \mathrm{~min}$, which was significantly shorter than that obtained in Altemeier procedure $(111.0 \pm 14.2 \mathrm{~min} ; t=5.26, p<0.01)$. Moreover, the Delorme procedure was accompanied by a significantly lower intraoperative blood loss $(20.8 \pm 6.5 \mathrm{ml})$ relative to the Altemeier therapy $(61.7 \pm 9.4 \mathrm{ml}, t=14.98, p<0.01)$. Notably, we found no significant differences with regards to incidence of postoperative complications, including bleeding, anastomotic stricture, anastomotic leakage, 
urinary retention, and urinary tract infection between the Delorme [16\% (3/19)] and Altemeier [20\% (3/15)] groups $(=0.10, p=0.75)$. However, the Delorme procedure was accompanied by significantly shorter postoperative hospital stay $(8.4 \pm 1.5$ days $)$ than the Altemeier therapy $(11.0 \pm 2.2$ days $)(t=4.13, p<0.01)$ (Table 4).

\section{Follow-up data}

There were no significant differences in follow-up times between the Delorme ( $16.3 \pm 2.3$ months) and Altemeier (15.0 \pm 3.3 months) groups, $(t=1.38, p=0.18)$. Similarly, the overall success rate was not significantly different between the Delorme (89.5\%) and Altemeier (86.7\%)groups $(=0.06, p=0.80)$ (Table 5 and Fig.3). Compared with before operation, Notably, Wexner constipation scores significantly decreased in both groups (Delorme $=23.6 \pm 2.5$ vs. $11.0 \pm 2.0, t=24.71, p<0.01$; Altemeier $=23.5 \pm 1.3$ vs.9.3 $\pm 1.7, t=13.8$, ,$p<0.01$ ) (Table 6). Conversely, we found no statistically significant differences in postoperativeWexner constipation scores between the two groups $(t=1.39, p=0.21)$. However, both groups exhibited significantly lowerpostoperative Wexner fecal incontinence scale scores than preoperative (Delorme $=14.8 \pm 1.5$ vs.6.2 $\pm 0.8, t=14.10, p<0.01$; Altemeier $=15.6 \pm 1.1$ vs.6.8 $\pm 2.3, t=10.2, \square p<0.01)$. However, differences between the groups were not statistically significant $(t=0.60, p=0.58)$ with regards to the postoperative Wexner fecal incontinence scale scores (Table 7).

\section{Discussion}

At present, several types of surgical methods, classified into either perineal and abdominal categories, have been developed for treatment of rectal prolapse. For perineal approaches, the latest guidelines by the American Society of Colon and Rectal Surgeons have recommended that Delorme procedure is suitable for patients with a prolapse length of less than $5 \mathrm{~cm}$, while the others should be subjected to Altemeier operation ${ }^{[11]}$. One of the main parameters used to assess efficacy of rectal prolapse surgery is the rate of recurrence. In the present study, patients subjected to Delorme procedure exhibited a lower recurrence rate and longer average follow-up time than those who underwent Altemeier operation. However, no significant differences were observed with regards to recurrence rates between the groups. This was consistent with previously reported recurrence rates following Delorme procedure (range, $6.85 \sim 40 \%)^{[12 ~ 14]}$. This difference in rates may be attributed to varying inclusion criteria, relevant instruments used, surgical skills and the length of follow-up applied across studies. On the other hand, recurrence rates after Altemeier procedure ranged from 0 to $39 \%$, and these may be attributed to various factors, such as age at surgical treatment, operative technique, length of the resected intestine and duration of prolapse ${ }^{[15 ~ 18]}$. Our results were consistent with the findings of a previous randomized controlled trial, comprising 102 and 99 patients who underwent Altemeier and Delorme procedures, respectively, which revealed similar recurrence rates after both approaches ${ }^{[19]}$. Comparative recurrence rates have also been achieved using either procedure ${ }^{[10,19]}$. However, Altemeier procedure has been associated with increased incidence of anastomotic leakage ${ }^{[16]}$. 
To date, only a handful of studies have evaluated quality of life after surgery in rectal prolapse patients. In the present study, patients who underwent either Delorme or Altemeier surgery exhibited improved fecal incontinence and alleviated constipation symptoms. These findings were consistent with Barber et al. [20] who found significant correlation between the absence of rectal prolapse symptoms postoperatively with a patient's assessment of overall improvement. The goals of Delorme or Altemeier procedure for patients with rectal prolapse are the surgical repair of prolapse and to relieve the symptom of fecal incontinence and constipation, which eventually improves the quality of life. Notably, the Delorme procedure was accompanied by shorter operative times, less intraoperative blood loss and shorter postoperative length of hospital stay, relative to Altemeier surgery. At the same time, we found no significant differences in incidence of postoperative complications, including bleeding, anastomotic stricture, anastomotic leakage, urinary retention and urinary tract infection, between the two groups, although there was one case (each) of bleeding, urinary retention, and urinary tract infection after Delorme operation. On the other hand, 3 cases (one each) exhibited bleeding, anastomotic stricture, and anastomotic leakage after Altemeier procedure. These results were consistent with previous reports ${ }^{[14,21]}$. The anastomotic leak recovered with conservative management, including bowel rest and total parenteral nutrition with or without intravenous antibiotics, with the resulting anastomotic stricture resolved by endoscopic dilatation. The remaining 4 cases also healed under conservative treatment. Altemeier procedure contains a transanal full-thickness resection of the prolapsed rectosigmoid and a coloanal anastomosis, while Delorme procedure only comprises resection of the mucosa. In principle, the Delorme procedure is not accompanied by anastomotic leak .

In summary, our results affirm the efficacy and safety of both Altemeier and Delorme procedures for treatment of rectal prolapse. Consequently, both procedures can improve defecation status in patients with faecal incontinence and constipation. Notably, Delorme procedure is superior to Altemeier surgery, for patients with mild prolapse, owing to its quicker recovery times, shorter hospital stay, and occurrence of fewer anastomotic complications.

\section{Declarations}

Author contributions HDW drafted the manuscript; ZS conceived of the study, and participated in its design and coordination, do the operation and helped to draft the manuscript; XFZ participated in the design of the study and performed the statistical analysis; SXS participated in the operations.

Funding This work was supported by funds from the Public Project of Zhejiang Science and Technology Department (Grant No. LGF20H030002) and Pilot Project from the Science and Technology Bureau of Hangzhou (Grant No. 20171226Y17).

Data availability Raw data were generated at The Third People's Hospital of Hangzhou. Derived data supporting the fndings of this study are available from the corresponding author [ZS] on request.

Conflict of interest The authors declare that they have no conficts of interest or fnancial ties to disclose. 
Ethics approval All procedures performed in studies involving human participants were in accordance with the ethical standards of the institutional and/or national research committee, and with the 1964 Helsinki Declaration and its later amendments or comparable ethical standards.

\section{References}

1. Emile SH, Elbanna H, Youssef M, Thabet W, Omar W, Elshobaky A, et al. Laparoscopic ventral mesh rectopexy vs Delorme's operation in management of complete rectal prolapse: a prospective randomized study. Colorectal Dis. 2017 Jan;19(1):50-57. doi: 10.1111/codi.13399.

2. van lersel JJ, Formijne Jonkers HA, Paulides TJC, Verheijen PM, Draaisma WA, Consten ECJ, et al. Robot-Assisted Ventral Mesh Rectopexy for Rectal Prolapse: A 5-Year Experience at a Tertiary Referral Center. Dis Colon Rectum. 2017 Nov;60(11):1215-1223. doi:

10.1097/DCR.0000000000000895.

3. Adusumilli S, Gosselink MP, Fourie S, Curran K, Jones OM, Cunningham C, et al. Does the presence of a high grade internal rectal prolapse affect the outcome of pelvic floor retraining in patients with faecal incontinence or obstructed defaecation?Colorectal Dis. 2013 Nov;15(11):e680-5. doi: 10.1111/codi.12367.

4. Youssef M, Thabet W, El Nakeeb A, Magdy A, Alla EA, El Nabeey MA, et al. Comparative study between Delorme operation with or without postanal repair and levateroplasty in treatment of complete rectal prolapse.Int J Surg. 2013;11(1):52-8. doi: 10.1016/j.ijsu.2012.11.011.

5. Hawkins AT, Olariu AG, Savitt LR, Gingipally S, Wakamatsu MM, Pulliam S, et al. Impact of Rising Grades of Internal Rectal Intussusception on Fecal Continence and Symptoms of Constipation. Dis Colon Rectum. 2016 Jan;59(1):54-61. doi: 10.1097/DCR.0000000000000510.

6. Tou S, Brown SR, Nelson RL. Surgery for complete (full-thickness) rectal prolapse in adults. Cochrane Database Syst Rev. 2015 Nov 24;2015(11):CD001758. doi: 10.1002/14651858.CD001758.pub3.

7. Barfield LR. Perineal Approaches to Rectal Prolapse. Clin Colon Rectal Surg. 2017 Feb;30(1):12-15. doi: 10.1055/s-0036-1593432.

8. Lu M, Yang B, Liu Y, Liu Q, Wen H. Procedure for prolapse and hemorrhoids vs traditional surgery for outlet obstructive constipation. World J Gastroenterol. 2015 Jul 14;21(26):8178-83. doi: 10.3748/wjg.v21.i26.8178.

9. Fang SH, Cromwell JW, Wilkins KB, Eisenstat TE, Notaro JR, Alva S, et al. Is the abdominal repair of rectal prolapse safer than perineal repair in the highest risk patients? An NSQIP analysis. Dis Colon Rectum. 2012 Nov;55(11):1167-72. doi: 10.1097/DCR.0b013e31826ab5e6.

10. Javed MA, Afridi FG, Artioukh DY. What operation for recurrent rectal prolapse after previous Delorme's procedure? A practical reality. World J Gastrointest Surg. 2016 Jul 27;8(7):508-12. doi: 10.4240/wjgs.v8.i7.508.

11. Bordeianou L, Paquette I, Johnson E, Holubar SD, Gaertner W, Feingold DL, et al. Clinical Practice Guidelines for the Treatment of Rectal Prolapse. Dis Colon Rectum. 2017 Nov;60(11):1121-1131. doi: 
10.1097/DCR.0000000000000889.

12. Emile SH, Elbanna H, Youssef M, Thabet W, Omar W, Elshobaky A, et al. Laparoscopic ventral mesh rectopexy vs Delorme's operation in management of complete rectal prolapse: a prospective randomized study. Colorectal Dis. 2017 Jan;19(1):50-57. doi: 10.1111/codi.13399.

13. Parés D, Drami I, Adams K, Grossi U, Suliman I, Knowles CH. Use of the Harmonic scalpel for Delorme's procedure. Colorectal Dis. 2017 Jun;19(6):0232-0234. doi: 10.1111/codi.13688.

14. Leo CA, Campennì P, Hodgkinson JD, Rossitti P, Digito F, De Carli G, et al. Long-Term Functional Outcome after Internal Delorme's Procedure for Obstructed Defecation Syndrome, and the Role of Postoperative Rehabilitation. J Invest Surg. 2018 Jun;31(3):256-262. doi:

10.1080/08941939.2017.1300714.

15. Tiengtianthum R, Jensen CC, Goldberg SM, Mellgren A. Clinical outcomes of perineal proctectomy among patients of advanced age. Dis Colon Rectum. 2014 Nov;57(11):1298-303. doi: 10.1097/DCR.000000000000022.

16. Pinheiro LV, Leal RF, Coy CS, Fagundes JJ, Martinez CA, Ayrizono Mde L. Long-term outcome of perineal rectosigmoidectomy for rectal prolapse. Int J Surg. 2016 Aug;32:78-82. doi: 10.1016/j.ijsu.2016.06.040.

17. Elagili F, Gurland B, Liu X, Church J, Ozuner G. Comparing perineal repairs for rectal prolapse: Delorme versus Altemeier. Tech Coloproctol. 2015 Sep;19(9):521-5. doi: 10.1007/s10151-015-1337-y.

18. Kim M, Reibetanz J, Schlegel N, Krajinovic K, Köstler H, Germer CT, et al. Recurrence after perineal rectosigmoidectomy: when and why? Colorectal Dis. 2014 Nov;16(11):920-4. doi: 10.1111/codi.12756.

19. Senapati A, Gray RG, Middleton LJ, Harding J, Hills RK, Armitage NC, et al. PROSPER: a randomised comparison of surgical treatments for rectal prolapse. Colorectal Dis. 2013 Jul;15(7):858-68. doi: 10.1111/codi.12177.

20. Barber MD, Brubaker L, Nygaard I, Wheeler TL, Schaffer J, Chen Z, et al. Defining success after surgery for pelvic organ prolapse. Obstet Gynecol. 2009 Sep;114(3):600-609. doi: 10.1097/AOG.0b013e3181b2b1ae.

21. Kim M, Reibetanz J, Schlegel N, Germer CT, Jayne D, Isbert C. Perineal rectosigmoidectomy: quality of life. Colorectal Dis. 2013 Aug;15(8):1000-6. doi: 10.1111/codi.12214.

\section{Tables}


Table 1

Patient Demographics

\begin{tabular}{|c|c|c|c|c|}
\hline Parameter & Delorme & Altemeier & $t$ or $\mathrm{X}^{2}$ & $p$-value \\
\hline Age(years) & $62.0 \pm 6.2$ & $60.6 \pm 6.5$ & $t=0.64$ & 0.53 \\
\hline \multicolumn{5}{|l|}{ Sex } \\
\hline male & $7(36.8 \%)$ & $4(26.7 \%)$ & \multirow[t]{2}{*}{$\mathbf{X}^{2}=0.40$} & \multirow[t]{2}{*}{0.53} \\
\hline female & $12(63.2 \%)$ & $11(73.3 \%)$ & & \\
\hline BMI & $23.6 \pm 2.4$ & $25.0 \pm 2.1$ & $t=1.72$ & 0.10 \\
\hline Duration of symptoms (years) & $10.0 \pm 2.7$ & $11.1 \pm 2.7$ & $t=1.14$ & 0.27 \\
\hline Squat maximal prolapse length $(\mathrm{cm})$ & $5.4 \pm 1.6$ & $9.3 \pm 2.3$ & $t=5.89$ & $<0.01$ \\
\hline ASA score & $2.0 \pm 0.8$ & $1.7 \pm 0.7$ & $t=1.24$ & 0.22 \\
\hline
\end{tabular}

Table 2

Occurrence of constipation in patients under operation

\begin{tabular}{|c|c|c|c|c|}
\hline Parameter & Delorme & Altemeier & $t$ or $\mathrm{X}^{2}$ & $p$-value \\
\hline Age(years) & $63.6 \pm 5.9$ & $56.5 \pm 6.5$ & $t=1.72$ & 0.13 \\
\hline \multicolumn{5}{|l|}{ Sex } \\
\hline male & 3 & 1 & \multirow[t]{2}{*}{$X^{2}=1.10$} & \multirow[t]{2}{*}{0.29} \\
\hline female & 2 & 3 & & \\
\hline Duration of symptoms (years) & $12.0 \pm 2.4$ & $11.0 \pm 2.9$ & $t=0.56$ & 0.60 \\
\hline Squat maximal prolapse length $(\mathrm{cm})$ & $6.6 \pm 0.9$ & $10.5 \pm 2.4$ & $t=3.42$ & 0.01 \\
\hline Wexner constipation score before surgery & $23.6 \pm 2.5$ & $23.5 \pm 1.3$ & $t=0.07$ & 0.95 \\
\hline The Wexner constipation score after surgery & $11.0 \pm 2.0$ & $9.3 \pm 1.7$ & $t=1.39$ & 0.21 \\
\hline
\end{tabular}


Table 3

Comparison of fecal incontinence in patients across operation groups

\begin{tabular}{|c|c|c|c|c|}
\hline Parameter & Delorme & Altemeier & $t$ or $\mathrm{X}^{2}$ & $\begin{array}{l}p- \\
\text { value }\end{array}$ \\
\hline Age(years) & $67.0 \pm 3.3$ & $64.2 \pm 3.7$ & $t=1.32$ & 0.22 \\
\hline \multicolumn{5}{|l|}{ Sex } \\
\hline male & 3 & 2 & \multirow[t]{2}{*}{$x^{2}=0.11$} & \multirow[t]{2}{*}{0.74} \\
\hline female & 3 & 3 & & \\
\hline Duration of symptoms (years) & $11.3 \pm 2.3$ & $12.4 \pm 2.4$ & $t=0.74$ & 0.48 \\
\hline Squat maximal prolapse length $(\mathrm{cm})$ & $5.3 \pm 1.2$ & $11.2 \pm 0.8$ & $t=9.13$ & $<0.01$ \\
\hline $\begin{array}{l}\text { The Wexner fecal incontinence scale score before } \\
\text { surgery }\end{array}$ & $14.8 \pm 1.5$ & $15.6 \pm 1.1$ & $t=0.95$ & 0.37 \\
\hline The Wexner fecal incontinence scale score after surgery & $6.2 \pm 0.8$ & $6.8 \pm 2.3$ & $t=0.60$ & 0.58 \\
\hline
\end{tabular}

Table 4

Postoperative outcomes

\begin{tabular}{|lllll|}
\hline Measure of outcomes & Delorme & Altemeier & $t$ or $\mathrm{X}^{2}$ & $p$-value \\
\hline Operative time (min) & $85.8 \pm 13.7$ & $111.0 \pm 14.2$ & $t=5.26$ & $<0.01$ \\
\hline Intraoperative blood loss $(\mathrm{ml})$ & $20.8 \pm 6.5$ & $61.7 \pm 9.4$ & $t=14.98$ & $<0.01$ \\
\hline Postoperative complications & $3 / 19$ & $3 / 15$ & $X^{2}=0.10$ & 0.75 \\
\hline Postoperative length of hospital stay (days) & $8.4 \pm 1.5$ & $11.0 \pm 2.2$ & $t=4.13$ & $<0.01$ \\
\hline
\end{tabular}

Table 5

Follow-up data

\begin{tabular}{|lllll|}
\hline Parameter & Delorme & Altemeier & tor $\mathrm{X}^{2}$ & $\boldsymbol{p}$-value \\
\hline Follow-up time (month) & $16.3 \pm 2.3$ & $15.0 \pm 3.3$ & $t=1.38$ & 0.18 \\
\hline Recurrence & $2 / 19$ & $2 / 15$ & $\mathrm{X}^{2}=0.06$ & 0.80 \\
\hline
\end{tabular}

Table 6

Wexner constipation scores in patients before and after operation

\begin{tabular}{|lll|}
\hline Parameter & Delorme & Altemeier \\
\hline The Wexner constipation score before surgery & $23.6 \pm 2.5$ & $23.5 \pm 1.3$ \\
\hline The Wexner constipation score after surgery & $11.0 \pm 2.0$ & $9.3 \pm 1.7$ \\
\hline $\mathrm{t}$ & 24.71 & 13.83 \\
\hline$p$-value & $<0.01$ & $<0.01$ \\
\hline
\end{tabular}


Table 7

Differences in fecal incontinence in patients before and after surgery

\begin{tabular}{|lll|}
\hline Parameter & Delorme & Altemeier \\
\hline The Wexner fecal incontinence scale score before surgery & $14.8 \pm 1.5$ & $15.6 \pm 1.1$ \\
\hline The Wexner fecal incontinence scale score after surgery & $6.2 \pm 0.8$ & $6.8 \pm 2.3$ \\
\hline $\mathrm{t}$ & 14.10 & 10.23 \\
\hline$p$-value & $<0.01$ & $<0.01$ \\
\hline
\end{tabular}

\section{Figures}
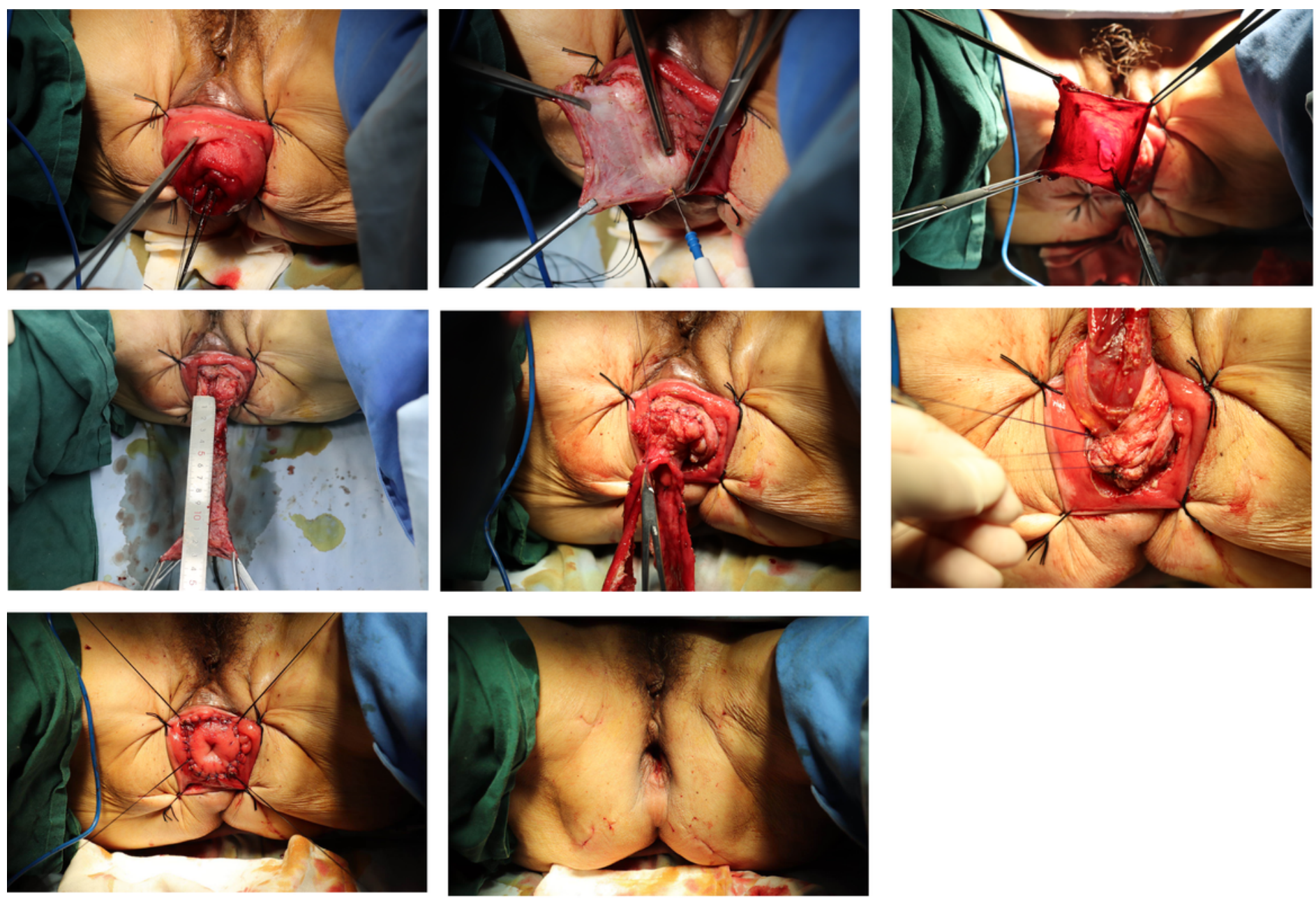

Figure 1

Legend not included with this version 

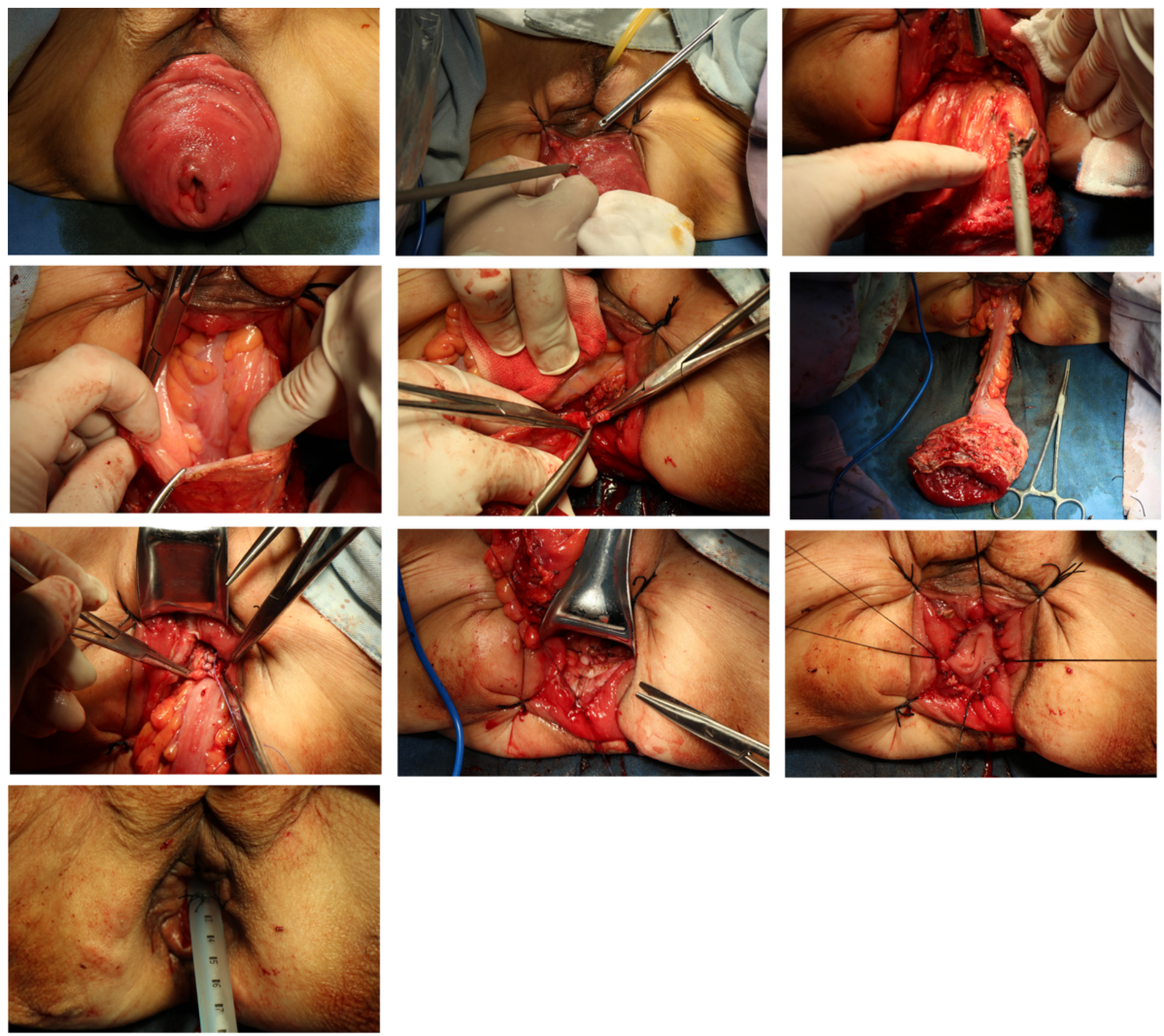

Figure 2

Legend not included with this version 


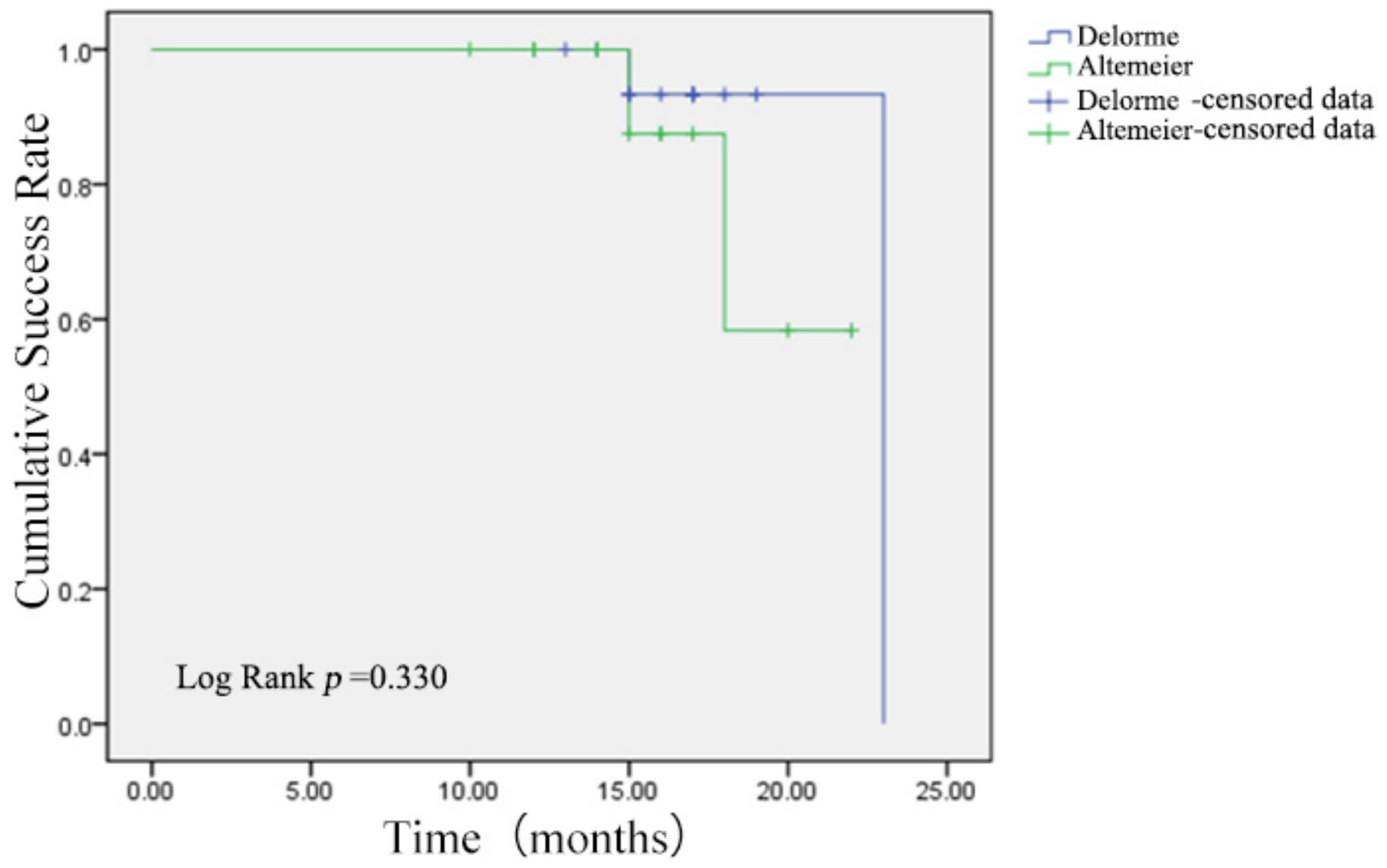

Figure 3

Legend not included with this version 